\title{
Promjena disciplinarnog okvira likovne kritike od šezdesetih godina dvadesetog stoljeća do danas
}

\author{
Lah, Nataša
}

Source / Izvornik: Institucije povijesti umjetnosti : zbornik 4. kongresa hrvatskih povjesničara umjetnosti, 2019, 137 - 141

Conference paper / Rad u zborniku

Publication status / Verzija rada: Published version / Objavljena verzija rada (izdavačev PDF)

https://doi.org/10.31664/z4khpu.19

Permanent link / Trajna poveznica: https://urn.nsk.hr/urn:nbn:hr:254:191030

Rights / Prava: Attribution 4.0 International/Imenovanje 4.0 međunarodna

Download date / Datum preuzimanja: 2023-04-26

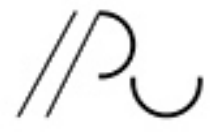

INSIIIUTZZA POVIJESTUMMETNOST
Repository / Repozitorij:

PODEST - Institute of Art History Repository

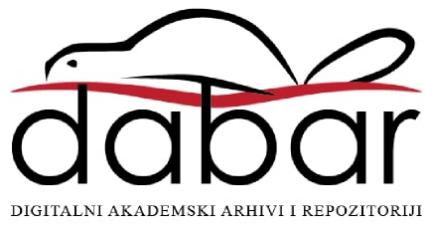




\section{Promjena disciplinarnog okvira likovne kritike od šezdesetih godina dvadesetog stoljeća do danas}

...djelo predlaže, čovjek raspolaže. ${ }^{1}$

U kontekstu rasprave o recepciji suvremene umjetnosti likovna je kritika tijekom zadnjih desetljeća imala skroman, granično komercijalan, nesustavan, a time i nesvrsishodan značaj u javnim medijima. ${ }^{2}$ Kritika na djelu kao dnevnonovinski format praćenja aktualne likovne scene time je posustala, dok su se različiti parakritički medijski formati grupirali duž nejasne disciplinarne granice između popularne kulture s jedne i povijesti umjetnosti, znanosti o slici i vizualnih studija s druge. Očito, tako zamišljeno, nestabilno razgraničenje ne dopušta jasnu diferencijaciju dvaju sasvim različita kriterija vrednovanja, onoga kontingèncije kulturnih prioriteta i onoga teorijske argumentacije. Potonja je uz iznimne dosege kritičkog esejizma obilježila kritiku moderne epohe, napose visokog modernizma, dok su kontingèncije kulturnih prioriteta našle svoj prostor u sveopćoj komodifikaciji društva. Dakle, između tržišnih interesa i medijskog senzacionalizma, vrijednosno neutralna izvještavanja i pratećih interpersonalnih i međuinstitucionalnih kompromisa, ili pak u sukobima različitih interesnih grupa u sustavu kulture i kulturnih politika autentični je smisao kritike na djelu izgubljen.

U radu se nastoji obrazložiti pretpostavka po kojoj je tako shvaćen, kaotični javni prostor bez konsenzusa o vrijednostima samo posljedica, ali ne i žarište duboke krize u kojoj se kritika našla. Kriza se locira ne toliko u javnoj, koliko u stručnoj i znanstvenoj recepciji suvremene umjetnosti, u samu jeziku kritičke djelatnosti, i to od vremena kada je njezin disciplinarni okvir doveden u pitanje promjenom tradicionalnoga poimanja prirode, smisla i značenja umjetnosti.

Počelo je sredinom dvadesetog stoljeća, prodorom niza novih i heterogenih umjetničkih praksi koje su iz temelja promijenile poimanje „standardnog” jezika umjetnosti i „standārda” na kojima počivaju jezici o umjetnosti. Eskaliralo je šezdesetih.

\section{Nataša Lah}

Odsjek za povijest umjetnosti Filozofski fakultet Sveučilište u Rijeci nlah@ffri.uniri.hr

https://orcid.org/oooo-ooo2-I725-633 I
I ROLAND BARTHES, Kritika i istina, Zagreb, Algoritam, 2009. [I966.], 44.

2 Vidi: NATAŠA LAH, Medijacijska funkcija umjetničke kritike, u: Ars Adriatica, 2 (20I2.), 269-28o. 
Gubitak stare matrice za primjenu poredbenih kriterija $u$ vrednovanju, podrazumijevao je potrebu za artikulacijom novih uvjeta, načina i kriterija vrednovanja. Ništa novo u povijesti, a ipak bitno drukčije u odnosu na ranije poznate paradigmatske prevrate. Kritičko izvođenje vrijednosnih kriterija prestalo je biti uvjet za stjecanje statusa umjetničkog djela, pa je stjecanje statusa poistovjećeno s vrednovanjem djela. Institucije, kompetentne za davanje statusa, postale su relevantne samim tim što su i same imale status umjetničkih institucija. ${ }^{3}$ Krug se zatvorio, a izvan njega ostala je kritika.

Granice novonastala „svijeta umjetnosti” ${ }^{4}$ pokazale su se kao institucionalno uporište za stjecanje statusa, ali, u svemu tome, upozorio je Nelson Goodman, ozbiljno se pobrkalo pitanje što je umjetnost, s pitanjem što je dobra umjetnost. ${ }^{5}$ Stjecanje statusa za suživot u zajednici „svijeta umjetnosti” ustrojio se na svojevrsnom paradoksu. S jedne strane, ne govorimo više o poredbenim kriterijima djelā u svijetu među drugim djelima, jer je umjetnost odbacila teret standardiziranih oblika vrednovanja, smatrajući ih ograničenima i ograničavajućima, ali je istovremeno pristala na institucionalni standard stručnog legitimiteta kao dovoljan uvjet za utvrđivanje granica svijeta umjetnosti. No pružanjem statusnog utočišta institucije svijeta umjetnosti ne samo da nisu osigurale nego su i onemogućile dalje propitivanje vrijednosnih svojstava djela u tako zamišljenu, malom prostoru stečena legitimiteta, koji se pretenciozno nazvao svijetom. Stjecanje statusa izvodilo se iz najšireg mogućeg spektra različitih interpretacija i metodologija, čime je kritika izgubila disciplinarni, poredbeno argumentacijski okvir. Prihvatimo li pritom da je kritika (ne samo etimološki nego i po smislu i značaju) razlučivanje, odlučivanje, a time i „ocjena” nečega, očekujemo da se temelji na nekom skupu vrijednosnih kriterija iz kojih se, uz pomoć disciplinarno dosljedne metodologije, razvija argumentacija s ciljem općeg važenja i kulturnog konsenzusa. Bez tih uvjeta u postupku analize umjetničkih djelā i njihovih prezentacija ne govorimo više o kritici, već o širokom spektru interpretativnih strategija. S obzirom, dakle, da se Dantoov „svijet umjetnosti”6 pokazao kao teorijski interpretiran, ali vrijednosno neomeđen prostor što ga naseljavaju djela kao arbitrarni teorijski objekti po sebi, kritika je uskoro i sasvim očekivano obezvrijeđena dodatnim zahtjevom što ga je Germano Celant ${ }^{7}$ artikulirao pozivom kritici da postane korisna, dakle-akritična. Sklapanjem prividno bezinteresna braka između umjetnosti i institucija, pozicija je kritike kao trećeg za nepoželjnu raspravu o vrijednostima postala suvišna.

Nedugo prije toga, u razdoblju visokog modernizma, imala je presudno hermeneutičku ulogu i po svom je povijesnom značaju bila u naponu snage. Čvrstom strukturom disciplinarnog okvira (a pritom se misli na jasne veze predmeta s metodama istraživanja) djelovala je u kulturno-povijesnom prostoru posredujući između elitne autonomije umjetnosti i kulturne potrebe za suučesništvom u tome. Posredničkim činom vrednovanja i autoritetom struke, kritika je kulturni prostor vidjela i kao označitelja i kao označenika vrijednosnog sustava.
Ovdje se misli na teorijsku platformu institucionalne teorije umjetnosti kako ju je postavio GEORGE DICKIE, napose $\mathrm{u}$ djelima: Defining Art, $\mathrm{u}$ : The American Philosophical Quarterly, 6/3 (I969.), 253-256 i Art and the Aesthetic: An Institutional Analysis, Ithaca, Cornell University Press, I974.

4 Sintagmom svijet umjetnosti, kako ju je artikulirao Arthur Danto I964. godine, ukazuje se na značaj interpretacije, ključne u slučajevima kada se neumjetnički predmet treba nužno kontekstualizirati, i to u svijetu povijesti, teorije umjetnosti i institucionalne umreženosti. Svijet umjetnosti podrazumijeva time da je mreža odnosa unutar kojih djelo nastaje sastavni dio toga djela.

5 NELSON GOODMAN, Načini svjetotvorstva, Zagreb, Disput, 2008. [I978.], 66.

6 ARTHUR DANTO, The Artworld, u: The Journal of Philosophy, 6I/I9 (I964.) (American Philosophical Association Eastern Division Sixty-First Annual Meeting), $57 \mathrm{I}-584$.

7 GERMANO CELANT, Per una critica acritica, u: Casabella, 343 (I969.), 42-44; u konačnoj verziji objavljeno u: NAC, I (I970.), 29-30. 
Doduše, sve je bilo primjereno hijerarhično ustrojenu sustavu moderne epohe. Utoliko je između elitnog i šireg kulturnog prostora u razdoblju visokog modernizma likovna kritika istodobno pomicala, ali i čuvala granice među kriterijima vrednovanja visoke i niske kulture.

No postupno se oformila nova, krajnje nejasna granica postmodernizma kada je o vrijednostima riječ, s potpuno promijenjenim kriterijem razgraničenja. Već spomenuta komodifikacija kulture pragmatično je pripomogla u prividnom brisanju stare granice između elitnog i širega kulturnog prostora. Nova je granica izolirala ovdje $i$ sada kao situaciju bez konsenzusa s poviješću i znanošću, gdje su se i povijest, i znanost, a time i budućnost ipak cinično relativizirale do neslućenih razmjera. Ostalo je nejasno je li takva pozicija postmodernizma proizašla iz otpora prema lažnom bratstvu umjetničkih i intelektualnih elita sa stvarnošću tijekom epohe modernizma, ili pak, kao love and hate odnos umjetnosti s moćnom industrijom kulture, koja ulažući u umjetnost istovremeno promiskuitetno izbjegava bilo kakav govor o vrijednostima, drugim riječima, o potrebi za uvijek boljim svijetom.

Kritika umjetnosti trebala bi biti spremna na stalnu transformaciju svojih načela pri sudaru s umjetničkim djelom, najavio je Walter Benjamin anticipirajući problem već tridesetih godina prošlog stoljeća. Njezin bi cilj u tom smislu trebao biti „otkrivanje nerealizirane budućnosti, inherentne umjetničkom djelu". Jer određeni kontekst sadašnjosti baca novo svjetlo na neki objekt prošlosti, i kroz tu „korespondenciju dviju temporalnosti” može se izbjeći nepoželjan smjer „ideološke iluzije linearnog progresivizma”. "No tako shvaćen status umjetničkog djela, smješten u argumentacijsku zajednicu sadašnjosti,ipak je izmaknuo u zonu kodnog, institucionalnog konsenzusa, dakle u novi oblik stare matrice ideoloških iluzija. S druge strane, umjesto ideološki konotirana institucionaliziranja, kritičkim bi strategijama prirodnije stanište bila znatno šira argumentacijska zajednica, obzirom da je i povijesno i znanstveno utemeljena na ideji projekta djela, za kakvu-takvu budućnost ili barem radi kakve-takve vjere u nju. Tako teleološki postuliran pojam projekta artikulirali su s nostalgijom i u jeku krize talijanski teoretičari, najprije Giulio Carlo Argan, ${ }^{9}$ a potom i Filiberto Menna. ${ }^{10}$

No ti svake pažnje vrijedni pokušaji da se protumači kulturni značaj likovne kritike tijekom druge polovine dvadesetog stoljeća nisu imali većeg utjecaja. Prije svega, kritika je kao drugostupanjski, posrednički medij izgubila svoj prvostupanjski oslonac u bilo kakvim čvrstim teorijskim postulatima na koje se uvijek oslanjala, ili ih je samostalno kreirala. Umjetničko djelo iz fokusa su izmjestile reprezentacije, kao „vidovi postojanja i modeli djelovanja”, kako ih definira Nicolas Bourriaud. ${ }^{11}$

Postteorijski koncept postmodernog vizualnog teksta umjesto argumentacijski raspoložene kritike ponudio je alternativnu, intertekstualnu otvorenost čitanja djela. Sve iz razloga koje je dobro definirala Linda Hutcheon, odredivši postmodernizam kao kulturni proces ili aktiunost, poetiku ili politiku, ${ }^{12}$ a ne kao megakulturni koncept koji podliježe određenoj ili određujućoj
8 RADE PANTIĆ, Valter Benjamin, u: Savremena marksistička teorija umetnosti, (ur.) Nikola Dedić, Rade Pantić, Sanela Nikolić, Beograd, Orion art, Fakultet za medije i komunikacije, 20I5., 59.

9 GiUlio CARLO ARGAN, Progetto e destino, Milano, Il Saggiatore, I965.

Io FILIBERTO MENNA, Il progetto moderno dell'arte, Milano, Politi, I988.

II NICOLAS BOURRIAUD, Esthétique relationnelle, Dijon, Les presses du reel, I998.

I2 LINDA HUTCHEON, A Poetics of Postmodernism, London, New York, Routledge, I988.; LINDA HUTCHEON, The Politics of Postmodernism, London, New York, Routledge, I989. 
definiciji. Prema riječima teoretičarke Hutcheon, riječ je o otvorenoj i stalno promjenjivoj teorijskoj strukturi, kojoj je Bourriaud naknadno pripisao status relacijske estetike. U tako postavljenu, permanentnom stadiju nesvršenosti ili eksperimenta, kritika je, prirodno, izgubila disciplinarni okvir jer se na upravo opisan način cjelovito redefinirao pojam umjetnosti.

Prve izvedenice promjene označio je ready-made tranzicijom iz neumjetničkog u umjetnički predmet. Nešto kasnije, neumjetnički predmet u neumjetničkom prostoru mogao je steći status umjetničkog djela. Time je konačno i radikalno napuštena ideja po kojoj bi institucionalizirani umjetnički prostor bio ekskluzivno mjesto čuvanja i pokazivanja djela, a da mu je prethodila teorijska ili kritička valorizacija. Galerije i muzeji postali su tek manje ili više adekvatan prostorni okvir reprezentacije.

No muzejsko-galerijski prostori time nisu izgubili statusni značaj, već su i sami licencirani kao najprominentniji institucionalizirajući faktor umjetnosti, posebno suvremene, a kustoska je, kao parakritička kompetencija, interpretativnu i hermeneutičku ulogu kritičkog razlučivanja zamijenila reprezentiranjem kao činom vrednovanja.

Teoretičar Donald Burton Kuspit o tome piše: „Pokazalo se da su kritičari umjetnosti postali dezorijentirani nasumičnim praćenjem programa koji su kreirale galerije i muzeji", ${ }^{13}$ preuzevši kritičku inicijativu, ali ne i strategiju. Žarište valorizacije umjetnosti izmjestilo se time iz disciplinarnog okvira kritike na područje reprezentacijskog eksperimentiranja i propitivanja. Isprobavanje nepoznatog, pisala je o tome i švedska kustosica Maria Lind, isključuje „potrebu za stalnim propitivanjem kakva će biti disciplinarna”, povijesno-umjetnička, ili pak javna recepcija, kako „bi se izbjegle odveć didaktične i trome institucije mainstreama zbog kojih je umjetnički eksperiment nepravično bio na marginama". ${ }^{14}$

Potrebu za promjenom, koju naslućuje Lindova u nastavku citiranog teksta, naznačio je Oskar Bätschmann u poglavlju naslovljenu Sustav interpretacijskih odnosa unutar knjige Uvod $u$ povijesnoumjetničku hermeneutiku.$^{15}$ Prije svega, riječ je o sve većoj potrebi za komunikacijom suvremene umjetnosti u prostoru javne i stručne recepcije, a kako se komunikacija odvija u argumentacijskoj zajednici, ona nužno obuhvaća povijesno objašnjenje, promatranje i kritičku provjeru odabrane argumentacijske aparature. Važnost je likovne kritike time, premda skromno, ipak ponovo naznačena, dok je dalja razrada inicijative moguća jedino u uvjetima promjene disciplinarnog fokusa likovne kritike.

Kritika u novom ključu treba se prilagoditi promjeni ideje o tome što je umjetnost danas. Pišući o „novoj kritici” još davne I965. godine, Roland Barthes takvu je zamisao artikulirao riječima: "[...] kritici ne treba da sudi, dovoljno je, umjesto da se jezikom služi, da o jeziku govori". ${ }^{16}$ Prijedlog dakako podrazumijeva da nismo pobrkali pitanje institucionalnog statusa umjetničkog djela s njegovim kulturnim efektom, epistemološkim, čulnim, poetičkim, estetskim ili etičkim dosezima. Uloga kritike u novom ključu pomaže intersubjektivnoj komunikaciji
I3 DONALD BURTON KUSPIT, Art criticism, u: Academic Dictionaries and Encyclopedias, 20Iо., http://universalium.academic.ru/2474Io/art_criticism (posjećeno I9. siječnja 20I2.).

I4 MARIA LIND, Ten Fundamental Questions of Curating: 4/ıo, Why Mediate Art?, (ur.) Jens Hoffman, Milano, Contrappunto S.R.L., 20II., 99-ıo8.

I5 OSKAR BÄTSCHMANN, Uvod u povijesnoumjetničku hermenutiku. Interpretacija slika, Zagreb, Scarabeus, 2004. [I984.], I59-I66.

I6 ROLAND BARTHES (bilj. I), II. 
ili, drugim riječima, pomaže dekonstruiranju nelagodna autoriteta samorazumljivosti u zajedničkom prostoru kulture. Umjesto rasprave o djelima, valja nam otvoriti raspravu o institucionalnim praksama, modelima reprezentacije, „vidovima postojanja i modelima djelovanja" umjetnika, o umjetnosti u odnosu sa svijetom, o estetskim, kulturnim, političkim i biopolitičkim vidovima umjetnosti. Kritici time ostaje da polemizira s komunikacijskim, jezičnim aspektima vizualnih reprezentacija.

Svjedočimo da je modernistički mišljenu aksiocentričnost ${ }^{17}$ oštra fokusa (gdje je autonomija djela, umjetnosti i umjetnika bila najveća među vrijednostima) današnja, difuzno raspršena ikonocentričnost izgurala na margine. Vrednovati je čini se ekscentrično, drugotno, strano i statično. Ali odricanje od neprimjenjivih i okoštalih normativnih sustava ne znači odricanje od vrijednosti sporazumijevanja, od konsenzusa u jeziku, a time i od jezika sama. Kritika se (opravdano je vjerovati) može obnoviti samo u otporu prema teroru ikonopokloničke, mrzovoljne šutnje o svemu, pa i o umjetnosti. Bilo bi idealno kada bi taj otpor bio naoružan argumentima i mobilan u kretanju kroz vrijeme bez prekidanja lente na slabim, žarišnim, kriznim točkama prevrata. ${ }^{18} \mathrm{U}$ protivnom, slabe bi argumentacije i fiksiranost u samo jednoj doktrini mogli još dublje pokopati status kritike u svijetu povijesti i teorije umjetnosti.

\section{() (1)}

Promjena disciplinarnog okvira likovne kritike od šezdesetih godina dvadesetog stoljeća do danas / Nataša Lah / CC BY / 4.0

DOI: https://doi.org/Io.3I664/z4khpu.I9
I7 Aksiocentričnost, za razliku od logocentričnosti, kojom je William John Thomas Mitchell okarakterizirao epohu koja je prethodila vizualnom i(li) slikovnom obratu, odnosno epohi ikonocentrizma, nije u tolikoj mjeri paradigma epohe, koliko jedan od metodoloških pristupa u istraživanju umjetnosti. Problem se šire razrađuje u: NATAŠA LAH, Vrijednosni opisi umjetnosti, u: Ars Adriatica, 6 (20I6.), 253-264.

I8 Aktualni primjeri teorijskog kidanja lente očituju se u proricanjima kraja umjetnosti, u distanciranju povijesti umjetnosti od srodnih znanstvenih područja kao što su znanost o slici ili vizualna kultura, kao i u drugim oblicima neupitnog nastojanja oko normativne metodologije, unatoč umjetničkim i teorijskim praksama koje su se razvijale u dugom razdoblju od šezdesetih godina dvadesetog stoljeća do danas. 